\begin{tabular}{|c|c|c|c|c|c|c|}
\hline \multirow{4}{*}{ Impact Factor: } & ISRA (India) & $=4.971$ & SIS (USA) & $=0.912$ & ICV (Poland) & $=6.630$ \\
\hline & ISI (Dubai, UAE & $=0.829$ & РИНЦ (Russia & $=0.126$ & PIF (India) & $=1.940$ \\
\hline & GIF (Australia) & $=0.564$ & ESJI (KZ) & $=8.716$ & IBI (India) & $=4.260$ \\
\hline & JIF & $=1.500$ & SJIF (Morocce & $=5.667$ & OAJI (USA) & $=0.350$ \\
\hline
\end{tabular}

\section{SOI: $1.1 /$ TAS $\quad$ DOI: $10.15863 /$ TAS \\ International Scientific Journal Theoretical \& Applied Science}

p-ISSN: 2308-4944 (print) e-ISSN: 2409-0085 (online)

Year: $2020 \quad$ Issue: $03 \quad$ Volume: 83

Published: $30.03 .2020 \quad$ http://T-Science.org
QR - Issue

QR - Article
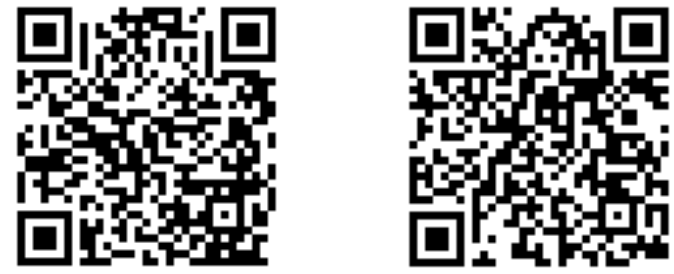

Fazu Keunimzhayevna Sherzhanova

Nukus branch Tashkent State agricultural university reseacher, Uzbekistan, Nukus

\title{
THE SYSTEM OF IMAGES IN THE TRAGEDY (On the basis of dramas by P. Tlegenov "Tragedy Begzhap" and "Revolution Dawn" of K. Yashin)
}

Abstract: In article the drama by the Karakalpak playwright P. Tlegenov "Tragedy Begzhap" and the drama by the Uzbek playwright "A revolution dawn" K. Yashin are considered. Accord of images and characters in these dramas is investigated.

Especially, in the spostavitelny plan Kaniyaz's image in the drama "Tragedy Begzhap" and Urganzhi's image in the drama "Revolution Dawn" is studied and the similarity of qualities of two heroes, even their actions in a plot of dramas is as a result defined. Besides, Eshmurat's images, Kuata, the Azat is considered more widely, Biyzhana and Perizata, special attention their labor fulfillments for the good of the Homeland is paid.

The playwright P. Tlegenov having enriched the tragedy with various events, improved complexity of drama koflikt and sharp turn of drama actions. In the tragedy bloody fights for a new way of life instead of old are described heroes face various threats. Fight between life and death is represented through the strong tragical conflict. The hero who passed through a certain dramatic nature in the life napravlyattsya on the correct and true way through understanding kind from angry, good from bad. At the same time, in the play fight of large natures of historical value against invincible disagreements is described. The author with skill involves this position in the tragedy, could represent authentically psychology of heroes and their action. Since plots of the first picture of the tragedy to the last picture characters of heroes are authentically created. In it there are no fantastic and fantastic phenomena which would naskuchat the audience. Characters are authentically revealed through each image.

Key words: dramaturg, idea, genre, herois, character, repertoire, personage, theater.

Language: Russian

Citation: Sherzhanova, F. K. (2020). The system of images in the tragedy (On the basis of dramas by P. Tlegenov "Tragedy Begzhap" and "Revolution Dawn" of K. Yashin). ISJ Theoretical \& Applied Science, 03 (83), 210-216.

Soi: http://s-o-i.org/1.1/TAS-03-83-41

Doi: crossef https://dx.doi.org/10.15863/TAS.2020.03.83.41

Scopus ASCC: 1208.

\section{СИСТЕМА ОБРАЗОВ В ТРАГЕДИИ}

(На основе драм П.Тлегенова «Трагедия Бегжап» и «Заря революции» К.Яшина)

Аннотация: В статье рассматривается драма каракалпакского драматурга П.Тлегенова «Трагедия Бегжап» совместно с драмой узбекского драматурга К.Яиина «Заря револючии». Идет речь о соответствии композиционного строя драм, о созвучии образов и характеров. Особенно, в споставительном плане изучается образ Канияза в драме «Трагедия Бегжап» и образ Урганжи в драме «Заря револючии» и в результате определена схожесть качеств двух героев, даже их действий в сюжете драм. Кроме того, шире рассматривается образы Еимурата, Куата, Азата, Бийжана и Перизата, уделяется особое внимание их трудовым свершения во благо Родины.

Драматург П.Тлегенов обогатив трагедию различными событиями, усовершенствовал сложностью драматических кофликтов и резким поворотом драматических действий. $B$ трагедии описываются кровавые бои за новый образ жизни вместо старого герои сталкиваются с различными угрозами. Борьба между жизнью и смертью изображается через сильный трагедийный конфликт. Герой, прошедший через определенный драматизм в своей жизни направлятется на правильный и истинный путь через осознания доброго от злого, хорошего от плохого. Вместе с тем, в пьесе описывается борьба крупных характеров 


\begin{tabular}{|c|c|c|c|c|c|c|}
\hline \multirow{4}{*}{ Impact Factor: } & ISRA (India) & $=4.971$ & SIS (USA) & $=0.912$ & ICV (Poland) & $=6.630$ \\
\hline & ISI (Dubai, UAE & $=0.829$ & РИНЦ (Russia) & $=0.126$ & PIF (India) & $=1.940$ \\
\hline & GIF (Australia) & $=0.564$ & ESJI (KZ) & $=8.716$ & IBI (India) & $=4.260$ \\
\hline & JIF & $=1.500$ & S.JIF (Morocco) & $=5.667$ & OAJI (USA) & $=0.350$ \\
\hline
\end{tabular}

исторического значения с непобедимыми разногласиями. Эту свою позииию автор с мастерством вовлекает в трагедию, смог достоверно изобразить психологию героев и их действия. Начиная с сюжетов первой картины трагедии до последней картины достоверно созданы характеры героев. В ней нет фантастических и сказочных явлений, которые бы наскучали бы зрителей. Через каждый образ достоверно раскрыты характеры.

Ключевые слова: трагедия, идея, жанр, драма, монолог, драматург, герой, образ, характер, репертуар, персонаж, театр.

\section{Введение}

Драматургия появилась в истории каракалпакской литературы в 20-годах прошлого века, на сегодняшний день эта отрасль обогатилась разными жанрами, и в течение периода своего развития прошла несколько этапов. Периоды развития можно разделить на 4 этапа:

Первый период: (1926-1930 гг)

Второй период: (1930-1960-гг.)

Третий период: (1960-1991-гг.)

Четвертый период: Драматургия в годы независимости.

За эти годы каракалпакская драматургия пройдя испытания временем в результате постоянных поисков и сложного труда, нашла свой путь и открыла новые грани, способы творчества. А также, драмы, написанные в духе любви к Родине, прославляющие дружбу народов, милосердие и заботу, человечность, пронизанные патриотическими идеями нашли достойное место в сердцах читаталей (зрителей). Особенно, комедии и драмы Н.Давкараева «Алпамыс», Ж.Аймурзаева «Бердах», А.Бегимова и Т.Алланазарова «Ғәрип ашық» («Влюбленный»), А.Шамуратова и И.Юсупова «Қырық кыз» («Сорок девушек»), С.Хожаниязова «Сүймегенге сүйкенбе» («Насильно миль не будешь»), К.Рахманова «Келин» («Невеста») и других, которые заняли свое достойное место в золотом фонде каракалпакского театра, и регулярно ставится предлагается зрителям.

Как всем известно, драматические произведения в основном делятся на трагедию, комедию и драму.

В мировой литературе произведения Эсхила «Прикованный Прометей» [21], Софокла «Царь Эдип» [14], Еврипида «Медея» [8], Шекспира «Гамлет» [9], «Отелло», «Ромео Жульетта» [17] созданы в жанре трагедии и являются классическими произведениями. Если обратить внимание содержанию и идейным особенностям произведений, написанных в жанре драмы в каракалпакской литературе, то становимся свидетелями, что создавались драмы, связанные в основном с историческими трагедиями. Исторические трагедии «Ерназар алакоз» (С.Мажийтов) [5, с. 13], «Тазагул» (Р.Мажитов) [1, c. 36], «Трагедия Бегжап» (П.Тилегенов) [16, с. 107].
Айдос баба» (Т.Алланазаров, на основе романа «Несчастные» Т.Кайыпбергенова) [2], «Ерназар Алакоз» (А.Уталиев) [18] на сегодняшний день имеет важное значение в каракалпакской драматургии.

Среди этих исторических трагедий «Трагедия Бегжап» П.Тлегенова в свое время оценивался высоко, почти всеми специалистами. В частности, в статье под названием «Оптимистическая трагедия» Б.Турсынова, в труде известного режиссёра, драматурга и ученого Т.Алланазарова «Театр и драматургия» приводятся положительные и ценные отзывы о трагедии и свидетельствует о большом опыте автора. Трагедия хоть и создана на основе объязательной политики бывшего советского периода, в нем изображаются такие качества, как человечность, честность и мужество и несомненно, имеет положительное влияние на сознание каждого читателя (зрителя).

К сожалению, во времена бывшего союза, каждому художественному произведению было свойственно то, что главные герои должны были быть объязательно партийными работниками, партийные и комсомольские организации вмешивались почти во все дела, даже общества. Политика и идеология ставились на первое место, внутренний мир человека остался в глубине лабиринта [12, с. 116, 117].

Талантливые люди нашего народа были поставлены в определенную рамку, драмы создавались на основе формы, установленной партией и правительством. Поэтому темы, конфликты, характеры, образы в драматургии повторялись не раз. Каждый драматург создает драму, комедию или трагедию исходя из условий и среды обитания и предлагает народу исходя из своих возможностей и возможностей своего времени. Драматурги, пережившие этот исторический процесс по мере возможности создавали драмы, близкие к народной жизни.

Наука литературоведение в течение долгого времени сформировалось для изучения и исследования художественной литературы с общественной точки зрения, то теперь избегая имеющиеся научные рамки на основе эстетических требований стараются делать научный подход и научное отношение. В результате, художественный уровень многих произведений, и историческое место развития национальных эстетических воззрений ряда 


\begin{tabular}{|c|c|c|c|c|c|c|}
\hline \multirow{4}{*}{ Impact Factor: } & ISRA (India) & $=4.971$ & SIS (USA) & $=0.912$ & ICV (Poland) & $=6.630$ \\
\hline & ISI (Dubai, UAE & $=0.829$ & РИНЦ (Russia) & $=0.126$ & PIF (India) & $=1.940$ \\
\hline & GIF (Australia) & $=0.564$ & ESJI (KZ) & $=8.716$ & IBI (India) & $=4.260$ \\
\hline & JIF & $=1.500$ & S.JIF (Morocco) & $=5.667$ & OAJI (USA) & $=0.350$ \\
\hline
\end{tabular}

литературоведов указывает в простом виде [9, с. 27].

В драме «Трагедия Бегжап» в определении описанных эстетических и эмоциональных впечатлений, если обратить внимание на порядок создания на основе требований драмы, то становимся свидетелями, что трагедия написана на основе соответствующих требований. В ремарке трагедии указывается: «оптимистическая трагедия, состоящая из 4-х актов, 8- картин.

Начиная с первой картины и до последней картины трагедии указанные сюжеты, герои и характери созданы очень достоверно. В ней нет фантастических сюжетов, встречающихся в отдельных драмах или искусственных явлений, встречающиеся в сказках и лишних сцен которые наскучит зрителей. Через каждый образ достоверно раскрыты характеры.

Построение характеров в сценарии очень сложное явление. Чтобы понять героев, изучение человека и понять смысл произведения, добиться цели, развивать события требуют от писателя много труда. Следует определить характер каждого героя [19, с. 57]. Об этом отмечают в своих трудах исследователи казахской литературы С.Ордалиев [11], А.Тажибаев [15] и академик Р.Нургали [10].

Когда мы всесторонне анализировали отрицательного героя пьесы, образ Канияза - он самоуверенный, упрямый, жестокий, хитрый и жесткий, можно представить его как человека, бесстрашно говорящего в лицо человеку, что взбредет ему в голову. Единственная цель Канияза быть хозяином чужих судеб.

Он с первой же картины трагедии, хочет брать в ловушку юношу, комсомольца по имени Куат, когда приходит к пожилой женщине Бийжан в поисках Куата, хозяйка дома Бийжан сначала хочет спрятать юношу. Но, Канияз говорит ей: «Предупреждаю, если мы его сами найдем, будет плохо» [16, с. 110]. Азат вынужден был показать, где спрятался Куат. Вместо того, чтобы благодарить его, Канияз забирает единственную корову Бийжан. Мало того, увидев дочь Гулпаршын Бийжан апа не стесняясь говорит ее: «Чья дочь? Солнцеликая? Лунаокая?». Тогда в целях защитить ее, Азат говорит сразу: «Господин, это моя сестра», Канияз бессовестно спрашивает: Твоя сестра? Какая красивая» [16, с. 111] Судя из его слов, можно сказать о его бесчеловечности, бессердечности и жестокости. Куда ни идет Канияз, он несет беспокойство, его мир полон злобы. Когда его просят о милости, падают ему в ноги, вместо того оказать им милость, он наоборот, возвеличивая себя, еще сильнее усиливает свою жестокость. Его жестокость и превосходство над народом в драме выявляет антогонистический конфликт.
Он в первой же картине обращает внимание на Гулпаршын, чтобы добиться своей цели и в третьей картине драмы насильно забирает ее из дома. Мать Бийжан не в силах противоречить разбойникам, умоляет: «Кровопийцы, убейте лучше меня!». Канияз ей отвечает: (нагло с усмешкой) Хочешь умереть, на тебе ... [16, с. 103] моментально расстреливает. Увидев все происходящее, озлобленный Азат хочет отомстить им. Его останаваливает Куат и говорит: «Ты сделаешь себе хуже!». Но Азат не слушает его со словами: Убью всех подряд! [16, с. 104] и уходит в погоню за разбойниками.

В 3-ем акте пьесы, в четвертой картине уже станет известно, как Тошмыкхан влюбляется в Гулпаршын и хочет жениться на ней. Это можно узнать из беседы в картине с Турдыкылышем. Он повелевает Турдыкылышу доставить в дворец Гулпаршын, будет известно, что уже доставил девушку сам Канияз. На то Тошмык злится и говорит: «Он хочет мне перейти дорогу? Нет. Он не стоит такой красивой девушки, она достанется мне, приведи ее сейчас же сюда» [16, с. 76].

Когда он хотел добиться ее, взять ее силой, в это время приходит Канияз. Тошмык, чтобы понравиться девушке делает нажим на Канияз, хочет перед девушкой ее опозорить. «Кто просил тебя, убив родителей девушки, привезти ее насильно? Канияз вначале умоляет его: «Не трогайте, господин ее. Я для вас найду сто таких девушек, но ее оставьте мне». Тошмык на то говорит: «Других мне не надо. Себе оставь других! Такая красавица должна быть только моей! Между ними назревает резкий конфликт. Канияз противоречит ему и отвечает: «Не имеете право меня унижать». Озлобленный Тошмык тут же приказывает его убить. Канияз все равно упирается и не боясь хана говорит в лицо: «Одумайтесь, потом будет поздно» [16, с. 77].

Борьба двух мужчин за одну женщину и конфликты, возникшие вследствие этого встречается и в драме «Заря революции» К.Яшина. В драме «Заря революции» рассказывается как Урганжи кушбеги не может простить Акбарбая за то, что бай используя свое положение и богатство, когда-то забирает возлюбленную Урганжи. Спустя годы, он занимает должность у Амира, разбогатеет, но его не оставляет в покое мысль отомстить Акбарбаю, добиться расположения Айымжахан. Однажды он врывается в дом Акбарбая. Ханом Акбарбаю давно уготован приговор, Урганжи не сразу его наказывает, мстит он не спеша и хочет унизить его перед женой Айымжахан, издевается над Акбарбаем, обвиняет его в предательстве, в неверности хану. Допрашивает бая, не дожидаясь ответа, перед ним говорит Айымжахан: «Идите отдыхать. Знайте себе цену. Теперь вы высокочтимая, ваше превосходительство, не 


\begin{tabular}{|c|c|c|c|c|c|c|}
\hline \multirow{4}{*}{ Impact Factor: } & ISRA (India) & $=4.971$ & SIS (USA) & $=0.912$ & ICV (Poland) & $=6.630$ \\
\hline & ISI (Dubai, UAE & $=0.829$ & РИНЦ (Russia) & $=0.126$ & PIF (India) & $=1.940$ \\
\hline & GIF (Australia) & $=0.564$ & ESJI (KZ) & $=8.716$ & IBI (India) & $=4.260$ \\
\hline & JIF & $=1.500$ & S.JIF (Morocco) & $=5.667$ & OAJI (USA) & $=0.350$ \\
\hline
\end{tabular}

мудрено, кто знает может завтра станете королевой Бухары» [22, с. 31]. От этих слов Акбарбай теряет сознание, «Я дам вам за Айымжахан, все что хотитете. Пять тысяч! Десять тысяч! Сто тысяч!» На то Урганжи отвечает: «Весь мир у меня под ногами, на что мне твой сундук золота! Пусть это сокровище будет у меня во дворце». Он делает Акбарбаю душевный нажим, морально унижает и с наслаждением приказывает его убить.

Отличительной чертой этих двух драм в «Трагедии Бегжап» конфликт между Тошмык хан и Каниязом возникает случайно усиливается противоречие между ними. А в драме «Заря революции», Урганжи когда был сардаром чтобы добиться расположения Айымжахан не было у него ни богатства, ни должности. Айымжахан достанется Акбарбаю за счет богатства, и нескончаемого золота. В душе Урганжи с того момента возникает внутреннее противоречие к Акбарбаю. Эта внутренняя коллизия развивается, Урганжи не спеша ждет ослабления своей добычи, ждет как голодный волк, чтобы уничтожить врага. В драме «Заря революции» это противоречие дается в виде внутренней коллизии.

В «Трагедии Бегжап» когда Тошмык хан приговаривает к смерти Канияза, Кутлымурат бий с помощью своих нукеров освобождает его. Здесь поднимается резкий конфликт между Тошмык ханом и Кутлымурат бием. Разъяренному Тошмык хану обращается Кутлымурат бий «Тошмык! Ты не один, который просит Кунград. Нас удивляет, что из-за одной женщины, ты приговариваешь к смертной казни такого воина как Канияз» [16, с. 78].

Из этих слов Кутлымурата можно сделать вывод, что Канияз имеет свое место в дворце, его почитают и ценят. Вот, этими качествами Канияз схож с образом Урганжи в драме «Заря революции». В драме «Заря революции» дворцовые чиновники перед ханом кланяются в три погибели, Урганжи даже не кланяется, голову еле качает, торжественно покидает дворец [13, с. 66 , 67]. Амир Алимхан с ним решает самые важные вопросы и сильно на него опирается. Потому что, он и как Канияз имеет свое место во дворце Амира.

Образ Канияза в драме «Трагедия Бегжап» занимает важное место, драматург П.Тлегенов превращает его действия в случайные драматические столкновения, привлекает к себе внимание читателя и зрителя. Один из таких поднятых в драме конфликтов возникает в 4-акте, в 7-ой картине между Каниязом и Чейхунсуйлин. Чейхунсуйлин неожиданно ему говорит «с сегодняшнего дня со всеми своими людьми будешь служить у меня» [16, с. 91] и увидев на его руках много золота добавляет: «Хан велел мне, отправить ему много золота. Вот, нашлось и золото» не считаясь ним забирает его золото. Каниязу не пришлось по душе такое отношение «Я не дурак, чтобы терпеть такое отношение, я не дам золота самозванцу, который без роду и племени». Чейхунсуйлин требует от него подчинения по приказу Джунайид хана. А Канияз ему говорит: «Мне не действует сила такого приказа» на глазах у него разрывает приказ, надменно бросает на ходу: «Иди своей дорогой. Нами не может править чужестранец». Чейхунсуйлин с пистолетом бросается ему. В этот момент Турдыкылыш расстреливает Чейхунсуйлин и спасает Канияза. Еще раз Канияз спасается от смерти.

Как видно, автор в трагедии описывая жадных и жестоких чиновников, из-за этих отрицательных качеств между ними возникает противоречие. Кутлымурат бий, Канияз, Турдыкылыш, Перизат, Тошмык и Чейхунсуйлин, хотя они стремятся к одной цели, между ними нет единства и дружбы. Как указано выше, эти действия появляются между Тошмык и Каниязом, в результате этого Чейхунсуйлин расстреляет Тошмык. Подобный сюжет в драме повторяется в 7-ой картине, когда возникает сильное столкновение между Каниязом и Чейхунсуйлин приходит Турдыкылыш расстреляет Чейхунсуйлин. В этих картинах хоть и происходят схожие моменты, автор обогащает его разными историями и случаями, драматическими столкновениями и драматическими действиями.

В последней картине «Трагедии Бегжап» Канияз Гале Емельяновой, попавшей к ним в плен не дает даже воды, заставляет страдать. Он требует ее подчинения и служить ему. Жаждавшей воды и обессилевшей Гале вместо воды дает соленую воду. Канияз в это время через предательницу Перийзат узнает место сбора и время ухода, уезжающих в Москву молодежи, их с хитростью берет в ловушку. Он в конце пьесы мучает молодых людей, хочет узнать их тайны, планы на будущее, их цель, но не может добиться цели. Никто из попавших в плен, смело готовясь к смерти, не говорят о своих планах. Поскольку их цель, либо добиться поставленной цели, либо умереть-одно из них, нет другого пути. Среди них только Куат рискнув с быстротой отбирает наган Турдыкылыша, расстреливает сначала его, потом Перийзат, говоря: «Еще мы рассчитаемся с врагами» бросает себя в воду, спасается от них. А Ешмурат: смело смотрит в лицо смерти и говорит: «Хотя один из нас погиб, но нас много и мы добьемся цели!». Ауданбаев говорит: «Из камня вода не выйдет, хоть его сжимай изо всех сил, не надейся». На то Кутлымурат говорит: Да, сегодня же раскрою их тайну, камень разобью, отведите их!» молодых людей отводят на берег, а они начинают петь.

Ер өлсе де ели - халқь жасайды, 


\begin{tabular}{|c|c|c|c|c|c|c|}
\hline \multirow{4}{*}{ Impact Factor: } & ISRA (India) & $=4.971$ & SIS (USA) & $=0.912$ & ICV (Poland) & $=6.630$ \\
\hline & ISI (Dubai, UAE & $=0.829$ & РИНЦ (Russia & $=0.126$ & PIF (India) & $=1.940$ \\
\hline & GIF (Australia) & $=0.564$ & ESJI (KZ) & $=8.716$ & IBI (India) & $=4.260$ \\
\hline & JIF & $=1.500$ & SJIF (Morocce & $=5.667$ & OAJI (USA) & $=0.350$ \\
\hline
\end{tabular}

Ели ушын туўылван ер өлмейди!

Жьртқыш аңлар, қан қумарлар, зальмлар,

Дәуураныныз сирә құйтип келмейди!

Если и умрет герой - его народ живет,

Ради Родины он никогда не умрет!

Жестокие охотники, кровопийцы, злодеи,

Ваше время никогда не придет!

По мере как удалялись голоса, слышится звук, как два раза стреляют автоматом» [16, с. 94] автор приводит отрывок. Таким образом, персонажи трагедии героически погибают ради одной цели, умирают ради своей родной земли. В этом месте указан трагический финал трагедии Бегжап.

Аристотель отмечал, для трагедии «перемена счастья к несчастью - это происходит не от преступления, а от большой ошибки» [4, с. 55] и указал, что следует выбрать фабулу. В мировой литературе описание в драме «переход счастья в несчастье», вследствие большой трагической ошибки издавна считается особым признаком смысла трагедии. В качестве примера, в трагедии Шекспира «Отелло» поверив в слова хитрого Ягона, Отелло совершает сложную трагическую ошибку. Такой способ интриги мы можем встретить и в других классических произведениях мировой литературы. Автор П.Тлегенов тоже продолжая эту традицию, в результате хитрости Перийзат подвергаются к несчастью несколько молодежи, которые собирались учиться в Москве. Но, смерть молодых людей, ставших жертвами за Родину, поднимает оптимистический дух трагедии, закладывает основу, что в будущем начнется другая жизнь, светлое будущее народа.

В пьесе сначала рождается характеры, создается образ человека в результате противоречий. Каждый образ отличается друг от друга. Один из таких образов образ Бийжан ана в драме имеет важное место в развитии действий ради достижения основных целей героев. Этот образ по жанровой природе пьесы кажется трагедийным образом.

Это чувствуется в первой картине драмы, через образ Бийжан ана можно увидеть трагедию всего народа. Она качает колыбель внука, и сгрустью поет:

Ялваншы бул дүньяның,

Шенгели тырнап денемди,

Басқан жерим шоқ жальн,

Өртеп жақты жанылдыь,

Хәййиў, хฺәййй, хฺәйййим-ай!

Жақты күним жулдыззым-ай!

Терни бренного мира,

Колют все мое тело,

Куда не ступлю, везде огонь

Разжигает всю мою душу,

Хайиу, хайиу, хайиу-ай!
Яркая моя звезда! [16, с. 108] - эти строки передает, через колыбельную песню, чувствуется тяжелая женская доля, их мечты и чаяния. Этот образ хоть и создан на основе шаблона старого советского строя, драматург украшает этот образ глубинными человеческими качествами, которые влияют на человеческое сознание. Например, в первой картине пъесы Бийжан ана помогает спрятаться юноше Кууат, спасавшего от врагов. Азату, не согласившего с ней, говорит: «Не хорошо, когда страдает мусульманин, сынок [16, c. 109]. Но тут же, Азат очерняет большевиков, старается привлекать в свою сторону мысли матери. В его понятии комсомольцы - это люди с плохими намерениями и наносящие, вред народу. Поэтому их ненавидит. Азат говорит матери: «Большевики-иноверцы, хотят уничтожить царя и установить страну бедняков» [16, с. 110] на то отвечает мать Бийжан: «если не сказать, что иноверец, его цель хорошая». Из этого ответа Бийжан ана можно увидеть образ матери, ждущего в будущем от жизни что-то хорошее. В той картине, услышав спасшего товарищами Кууат, она говорит «как хорошо» [16, с. 111].

Мать Бийжан останется без мужа, без сына, без хозяйства из-за врагов. Но труднее всего было для нее, остаться без единственной дочери Гулпаршын. Она борется с захватниками, которые забирают насильно ее дочь. Разбойники, когда сказали ей «не подходи», она ответила: «нет не уйду, мужа моего убили, теперь убейте и меня» $[16$, c. 103] тут же ее расстреливает Канияз. В драме в результате таких трагедийных событий, встречающиеся в жизни, Азат учится различать хорошее и плохое. После смерти сестры, он уже знает, кто друг, кто враг. Он еще не различавший категорию людей, проходит через определенную драму.

Об образе Азат выдающийся ученый, известный режиссёр Т.Алланазаров в своем труде «Театр и драматургия» описывает так: «Действия, полные драматизма старушки Бийжан привлекает Азата, волновал его чистый внутренний мир» [3, с. 153].

В пьесе в образах Кууата и Ешмурата ярко проявляется характерные особенности. Образ Кууата - образ смелого джигита, который работает с умом, можно сказать дальновидный, рискованный герой. Он во второй картине пъесы сомневаясь в Азате, когда хотел наказать его, Кууат останавливает Ешмурата и других, «Постой Ешмурат, не будем без вины виноватыми». Тут Ешмурат злится: «Что? Он же хочет нас изловить» Кууат в задумчивости отвечает: «Он не понимает, что делает, по-моему не такой» [16, с. 114]. В результате его разумный действий он смог помочь Азату отличить правду от лжи.

Если Кууат дальновидный и рискованный парень, то Ешмурат решительный, при виде 


\begin{tabular}{|c|c|c|c|c|c|c|}
\hline \multirow{4}{*}{ Impact Factor: } & ISRA (India) & $=4.971$ & SIS (USA) & $=0.912$ & ICV (Poland) & $=6.630$ \\
\hline & ISI (Dubai, UAE & $=0.829$ & РИНЦ (Russia) & $=0.126$ & PIF (India) & $=1.940$ \\
\hline & GIF (Australia) & $=0.564$ & ESJI (KZ) & $=8.716$ & IBI (India) & $=4.260$ \\
\hline & JIF & $=1.500$ & SJIF (Morocco) & $=5.667$ & OAJI (USA) & $=0.350$ \\
\hline
\end{tabular}

несправедливости, может ошибаться в своих действиях, но честный и порядочный джигит. Это моно видеть в сцене, когда захватчики насильно забирают Гулпаршын и Ешмурат старается помочь ее в спасении. Остановившего его товарищам, говорит: «Пустите меня! Этих злодеев нужно остановить!». Сапар ему говорит: «Ты забыл нашу сегодняшнюю важную задачу? В решающий момент хочешь нас связать по рукам?» [16, c. 103].

Как отмечал великий критик Белинский «в драме все должно быть направлено к определенной цели, к важной задаче» [6, с. 89] - в трагедии образы имеют подобные характерные особенности, их действия направлены к одной цели.

Если сделать вывод, в драме «Трагедия Бегжап» изображается кровавые столкновения между старым и новым миром, герои проходят через опасности. Борьба между жизнью и смертью описывается через сильный трагедийный конфликт. Также, герой, проходивший через определенный драматизм, посредством различия хорошего от плохого выбирает правильный путь, идет в направлении к достижению цели. Известный писатель казахского народа Н.Габдуллин отмечает: «трагедия - самый сложный и ответственный жанр драматургии. Каждый печальный случай не может быть материалом для трагедийного конфликта» [7, с. 116] - так пишет автор, в этом жанре изображается сильные противоречия и столкновения характеров, имеющие историческое значение. Автор эту позицию с мастерством вовлекает в трагедию, смог достоверно создать психологию и действия героев. Пьеса в свое время имело важное место в истории каракалпакской драматургии, постоянно украшал репертуар театра, который несомненно служит развитию эстетических мыслей читателей и научных исследователей.

\section{References:}

1. Ajymbetov, K. (1963). Ocherki iz istorii karakalpakskoj sovetskoj dramaturgii [Sketches from history of the Karakalpak Soviet dramatic art]. Nukus: Karakalpakstan (In Karakalpak).

2. Allanazarov, T. (1992). Dedushka Ajdos. [Grandfather Aydos]. Nukus: Karakalpakstan (In Karakalpak).

3. Allanazarov, T. (1982). Teatr $i$ dramaturgija [Theater and dramatic art]. Nukus: Karakalpakstan (In Karakalpak).

4. Aristotel' (1927). Pojetika. [Poetics]. L. (In Rus.).

5. Bajnijazov, K. (1991). Sejfulgabijt Mazhijtov. [Seyfulgabiyt Mazhiytov]. Nukus: Karakalpakstan (In Karakalpak).

6. Belinskij, V.G. (1948). O drame i teatre [About the drama and theater] Moskva: Iskusstvo (In Rus.).

7. Gabdullin, N. (1968). Osnova proizvedenija jeto dejstvitel'nost' [The basis of the work is a reality] Almaty: Pisatel' (In Kazak).

8. Evripid (1985). Medeja [Euripedes. Medea]. Tashkent: Literatury i iskusstvo imeni Gafura Guljama (In Uzbek).

9. Juldashev, K. (2000). Chto takoe literaturovedenie? [What is the literary criticism?] // Tafakkur. Tashkent, № 3 (In Uzbek).
10. Nurgali, R. (2001). Iskusstvo drama [Iskusstvo drama] Almaty: Sanat (In Kazak).

11. Ordaliev, S. (1964). Ocherk kazahskoj dramaturgii [Sketch of the Kazakh dramatic art] Almaty: Zhazushy (In Kazak).

12. Utemuratov, F. (2007). Vremja $i$ dramaturg [Time and playwright] // Amudar'ja. Nukus (In Karakalpak).

13. Rizaev, O. (1997). Nabi Rahimov [Nabi Rakhimov] Tashkent: Literatury i iskusstvo imeni Gafura Guljama (In Uzbek).

14. Sofokl (1979). Car' Jedip [Tsar Oedipus] Tashkent: Literatury i iskusstvo imeni Gafura Guljama (In Uzbek).

15. Tazhibaev, A. (1971). Razvitie i formirovanie kazahskoj dramaturgii [Development and formation of the Kazakh dramatic art]. Almaty: Pisatel' (In Kazak).

16. Tlegenov, P. (1965). Tragedija Begzhap [Tragedy Begzhap] // Amudər'ja. Nukus. № 5, 6, 7 (In Karakalpak).

17. Tursunbaev, S. (2001). Istorija zarubezhnogo teatra [History of foreign theater]. Tashkent (In Uzbek).

18. Utaliev, A. (1997). Ernazar Alakoz [Ernazar Alakoz] Nukus: Karakalpakstan (In Karakalpak). 


\begin{tabular}{|c|c|c|c|c|c|c|}
\hline \multirow{4}{*}{ Impact Factor: } & ISRA (India) & $=4.971$ & SIS (USA) & $=0.912$ & ICV (Poland) & $=6.630$ \\
\hline & ISI (Dubai, UAE & $=0.829$ & РИНЦ (Russia & $=0.126$ & PIF (India) & $=1.940$ \\
\hline & GIF (Australia) & $=0.564$ & ESJI (KZ) & $=8.716$ & IBI (India) & $=4.260$ \\
\hline & JIF & $=1.500$ & SJIF (Morocec & $=5.667$ & OAJI (USA) & $=0.350$ \\
\hline
\end{tabular}

19. Hajdar, M. (2009). Masterstvo scenarista [Skill of the screenwriter] Nukus: Znanie (In Karakalpak).

20. Shekspir, V. (1983). Gamlet [Hamlet]. Tashkent: Literatury i iskusstvo imeni Gafura Guljama (In Uzbek).
21. Jeshil, (1978). Prikovannyj Prometej [The chained Prometheus].Tashkent: Literatury i iskusstvo imeni Gafura Guljama (In Uzbek).

22. Jashin, K. (1974). Zarja revoljucii [Revolution dawn]. Tashkent: Tashkent: Literatury i iskusstvo imeni Gafura Guljama (In Uzbek). 